\title{
SUPRIMENTO DE POTÁSSIO EM FUNÇÃO DA ADUBAÇÃO POTÁSSICA RESIDUAL EM UM LATOSSOLO VERMELHO DO CERRADO $^{(1)}$
}

\author{
Ciro Antonio Rosolem ${ }^{(2)}$, João Paulo Testa Moura Montans Vicentini ${ }^{(3)}$ \& Fábio Steiner ${ }^{(4)}$
}

\begin{abstract}
RESUMO
Em alguns solos com baixos teores de potássio trocável, formas não trocáveis participam do suprimento às plantas. Há evidências de que a disponibilização do K não trocável depende mais da demanda das plantas pelo nutriente do que das propriedades do solo. $O$ objetivo deste trabalho foi avaliar o suprimento e a exaustão de formas de $\mathrm{K}$ em um Latossolo Vermelho do Cerrado em decorrência da adubação potássica residual e do cultivo de Brachiaria ruziziensis (Syn. Urochloa ruziziensis). Amostras de solos foram coletadas na camada de 0-20 cm, em parcelas de um experimento de campo em que a soja vinha sendo adubada anualmente, por 10 anos, com $0,60,120$ e $180 \mathrm{~kg} \mathrm{ha}^{-1}$ de $\mathrm{K}_{2} \mathrm{O}$. Em casa de vegetação,

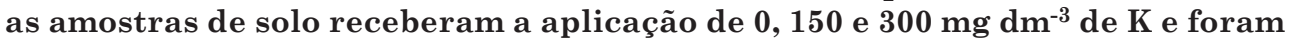
cultivadas com $B$. ruziziensis, com cinco cortes sucessivos. $O$ suprimento de $K$ às plantas dependeu mais do fertilizante recém-adicionado do que do efeito residual de adubações anteriores. O K não trocável foi responsável, ao longo do tempo, pela manutenção dos teores de $\mathrm{K}$ trocáveis e, na ausência de adubação potássica, constituiu a principal fonte de $\mathrm{K}$ para as plantas de B. ruziziensis. As plantas de B. ruziziensis possuem capacidade de extrair quantidade considerável de $\mathrm{K}$ do solo, confirmando sua importância como cultura de cobertura, na ciclagem do nutriente no solo.
\end{abstract}

Termos de indexação: Brachiaria ruziziensis, K não trocável, disponibilidade, fertilização.

(1) Pesquisa realizada com apoio financeiro da FAPESP. Recebido para publicação em 25 de outubro de 2011 e aprovado em 16 de julho de 2012.

(2) Professor Titular, Departamento de Produção Vegetal, Faculdade de Ciências Agronômicas, Universidade Estadual Paulista UNESP. Caixa Postal 237 CEP 18603-970 Botucatu (SP). E-mail: rosolem@fca.unesp.br

(3) Acadêmico do Curso de Engenharia Agronomica, FCA/UNESP. E-mail: garssa_jpv@hotmail.com

(4) Eng.-Agrônomo, M.Sc., Doutorando em Agronomia/Agricultura, FCA/UNESP. E-mail: fsteiner@fca.unesp.br 


\title{
SUMMARY: POTASSIUM SUPPLY AS AFFECTED BY RESIDUAL POTASSIUM FERTILIZATION IN A CERRADO OXISOL
}

\begin{abstract}
In some soils with low levels of exchangeable potassium, non-exchangeable forms can participate in plant supply. There is evidence that $K$ supply in non-exchangeable forms depends more on plant nutrient demand than on soil properties. The purpose of this study was to evaluate the supply and depletion of K forms in a Cerrado Oxisol, as affected by residual $K$ fertilization and successive cultivation of Brachiaria ruziziensis (Syn. Urochloa ruziziensis). Soil samples were collected in the 0-20 cm layer in plots of a field experiment installed in 2001, where soil had been fertilized for 10 years with 0 , 60,120 and $180 \mathrm{~kg} \mathrm{ha}^{-1}$ of $\mathrm{K}_{2} \mathrm{O}$. In a greenhouse, 0, 150 and $300 \mathrm{mg} \mathrm{dm}^{-3} \mathrm{~K}$ was applied to the soil samples and B. ruziziensis was grown and cut five times. The K supply of the plants depended more on the newly added fertilizer than on the residual effect of previous fertilization. The non-exchangeable $K$ is responsible, over time, for the maintenance of exchangeable $K$ levels and becomes the main source of $K$ for $\mathrm{B}$. ruziziensis plants in the absence of $K$ fertilization. Brachiaria ruziziensis plants have the capacity to absorb large amounts of $K$ from the soil, confirming the importance of this cover crop for soil nutrient cycling.
\end{abstract}

Index terms: Brachiaria ruziziensis, non-exchangeable $K$, available, fertilization.

\section{INTRODUÇÃO}

Em solos tropicais, a disponibilidade e a capacidade de suprimento de potássio (K) dependem da presença de minerais primários e secundários, da aplicação de fertilizantes e da capacidade de troca catiônica (CTC), além da ciclagem do nutriente pelas plantas. Em outras palavras, a disponibilidade depende das formas de Ke da quantidade armazenada em cada uma dessas formas (Rosolem et al., 1988), aspectos que contribuem para a movimentação e dinâmica do K no perfil do solo. De acordo com Sparks \& Huang (1985), o K do solo inclui K em solução, K trocável, K não trocável e $\mathrm{K}$ estrutural, e essas formas estão em equilíbrio, seguindo um gradiente em que diminui a sua disponibilidade.

Apesar de a recomendação para a adubação potássica ser baseada, principalmente, no teor de K trocável, duas outras formas de K (K liberado a partir de resíduos de culturas e K não trocável) podem migrar para a solução do solo, contribuindo para a nutrição das plantas em alguns solos em curto prazo (Rosolem \& Nakagawa, 1985; Rosolem et al., 1993; Calonego et al., 2005; Kaminski et al., 2007; Simonsson et al., 2007) e devem ser consideradas no sistema de produção (Garcia et al., 2008). Dessa maneira, para o adequado manejo da adubação potássica, é importante definir a disponibilidade das diferentes formas de $\mathrm{K}$ no solo às plantas e sua influência na dinâmica do K no perfil do solo. Isso porque a aplicação insuficiente de fertilizante pode levar ao esgotamento das reservas do solo (Rosolem et al., 1993; Singh et al., 2002; Öborn et al., 2005), e a aplicação excessiva pode intensificar as perdas por lixiviação (Rosolem et al., 2006, 2010), mesmo em solos com média e alta capacidade de troca catiônica (Ernani et al., 2007; Werle et al., 2008).
O cultivo de plantas com capacidade de extrair quantidades consideráveis de $\mathrm{K}$ e a adição de fertilizantes potássicos podem influir na relação entre as reservas de $\mathrm{K}$ do solo e na sua disponibilidade, acarretando alterações dos minerais potássicos do solo (Velde \& Peck, 2002; Pernes-Debuyser et al., 2003; Simonsson et al., 2009). Rosolem et al. (1993) constataram que a disponibilização do K não trocável em cinco solos tropicais, independentemente do tipo de solo, manteve equilibrados os níveis de $\mathrm{K}$ trocável do solo durante o desenvolvimento das plantas. No entanto, há evidências de que a disponibilidade das formas não trocáveis de $\mathrm{K}$ depende mais da demanda das plantas pelo nutriente do que das propriedades do solo, como textura e mineralogia (Kaminski et al., 2010). Garcia et al. (2008) constataram que a presença de Brachiaria brizantha em consórcio com o milho resultou em aumento na taxa de liberação do K não trocável do solo em comparação ao cultivo de milho solteiro, indicando que as plantas de braquiária possuem capacidade de induzir a liberação de $\mathrm{K}$ inicialmente presente em formas não trocáveis no solo, porém não há nenhum estudo que comprove essa inferência para a espécie Brachiaria ruziziensis (Syn. Urochloa ruziziensis).

A contribuição de diferentes formas de K às plantas tem sido comumente estimada por cultivos e, ou, cortes sucessivos (Rosolem et al., 1988; Kaminski et al., 2007; Fraga et al., 2009). No entanto, é desconhecida a contribuição dessas formas de K na nutrição de plantas em solos tropicais de textura média e com histórico de fertilização potássica.

Este trabalho teve como objetivo avaliar o suprimento e a exaustão de formas de $\mathrm{K}$ em um Latossolo Vermelho do Cerrado em decorrência da adubação potássica residual e do cultivo de Brachiaria ruziziensis (Syn. Urochloa ruziziensis) com cinco cortes sucessivos. 


\section{MATERIAL E MÉTODOS}

O experimento foi realizado em casa de vegetação no Departamento de Produção Vegetal, Faculdade de Ciências Agronômicas, UNESP, em Botucatu, SP $\left(22^{\circ}\right.$ $51^{\prime} \mathrm{S}, 48^{\circ} 26^{\prime} \mathrm{W}$ e altitude de $770 \mathrm{~m}$ ), no período de agosto de 2010 a março de 2011. Foram utilizadas amostras de um Latossolo Vermelho distrófico de textura média (Embrapa, 2006), com $210 \mathrm{~g} \mathrm{~kg}^{-1}$ de argila, coletadas da camada de $0-20 \mathrm{~cm}$ de profundidade, em um experimento de campo, onde a soja tinha sido cultivada e adubada anualmente com 0, 60, 120 e $180 \mathrm{~kg} \mathrm{ha}^{-1}$ de $\mathrm{K}_{2} \mathrm{O}$, durante 10 anos. A fração argila isenta de óxidos de ferro livres apresenta de 73 a $83 \%$ de caolinita e 14 a $18 \%$ de alofana, com teores menores que $3 \%$ de gibbsita. Para o experimento em casa de vegetação, foram coletadas amostras de solos representativas de cada uma das quatro repetições do experimento de campo. As análises químicas foram efetuadas seguindo indicações de Raij et al. (2001), e os resultados são mostrados no quadro 1. A correção da acidez foi realizada com calcário dolomítico $(\mathrm{CaO}=28 \%, \mathrm{MgO}=12 \% \mathrm{e}$ PRNT $=96 \%$ ), em quantidade equivalente para elevar a saturação por bases a 60 \% (Raij et al., 1997). Em seguida, o solo foi umedecido até alcançar $70 \%$ da capacidade de retenção de água e incubado por 30 dias. Posteriormente, o solo foi fertilizado com $80 \mathrm{mg} \mathrm{dm}^{-3}$ de $\mathrm{N}$ (ureia), $120 \mathrm{mg} \mathrm{dm}^{-3}$ de $\mathrm{P}$ (superfosfato triplo), $15 \mathrm{mg} \mathrm{dm}^{-3}$ de $\mathrm{S}$ (sulfato de cálcio), $2 \mathrm{mg} \mathrm{dm}^{-3} \mathrm{de} \mathrm{Cu}$ (sulfato de cobre), $2 \mathrm{mg} \mathrm{dm}^{-3}$ de $\mathrm{Zn}$ (sulfato de zinco) e $1 \mathrm{mg} \mathrm{dm}^{-3} \mathrm{de} \mathrm{B}$ (ácido bórico), transferido para vasos de polietileno com capacidade para $8,0 \mathrm{dm}^{3}$ e submetido ao cultivo de B. ruziziensis (Syn. Urochloa ruziziensis) com cinco cortes sucessivos.

O delineamento experimental empregado foi o de blocos ao acaso em esquema fatorial $4 \times 3$, constituídos por quatro doses de adubação potássica residual (do campo) e três doses de K aplicadas aos vasos em casa de vegetação, com quatro repetições. Os tratamentos em casa de vegetação constituíramse da aplicação de doses de 0,30 e $60 \mathrm{mg} \mathrm{dm}^{-3}$ de K antecedendo os cinco cortes de $B$. ruziziensis, totalizando a aplicação de 0,150 e $300 \mathrm{mg} \mathrm{dm}^{-3}$.
A semeadura de $B$. ruziziensis foi efetuada com 18 sementes por vaso. Sete dias após a emergência das plantas, fez-se um desbaste e foram deixadas seis plantas por vaso. O teor de água do solo foi monitorado diariamente e mantido próximo a $80 \%$ da capacidade de retenção. Para evitar eventuais perdas de água por percolação durante o processo de irrigação, foram usados vasos com base sem drenos. Após cada corte, os vasos foram fertilizados com $20 \mathrm{mg} \mathrm{dm}^{-3} \mathrm{de} \mathrm{N}, 40$ $\mathrm{mg} \mathrm{dm^{-3 }}$ de P, $5 \mathrm{mg} \mathrm{dm}^{-3}$ de S, $2 \mathrm{mg} \mathrm{dm}^{-3}$ de Cu e 2 $\mathrm{mg} \mathrm{dm}{ }^{-3} \mathrm{de} \mathrm{Zn}$. Aos 20 dias após cada corte, também foram aplicados $40 \mathrm{mg} \mathrm{dm}^{-3}$ de $\mathrm{N}$. A casa de vegetação não possuía controle automático de temperatura, porém foi realizado o controle parcial, com ventilação do ambiente e nebulização nos dias mais quentes. As condições ambientais durante a condução do experimento foram: temperaturas mínima e máxima do ar de 12,8 e $38,7^{\circ} \mathrm{C}$, respectivamente, e umidade relativa média do ar de $60 \%$.

Aos 42 dias após a emergência, as plantas de $B$. ruzisiensis foram cortadas a uma altura de $5 \mathrm{~cm}$ da superfície do solo. Os demais cortes também foram realizados aproximadamente 42 dias depois do corte anterior. No quinto corte, as plantas foram cortadas rente à superfície do solo e divididas em parte aérea e raízes. Em todos os cortes, o material vegetal coletado foi seco em estufa de circulação de ar a $60^{\circ} \mathrm{C}$ por $72 \mathrm{~h}$, pesado, moído e submetido à análise para determinação do teor de K, como descrito por Malavolta et al. (1997). A quantidade de K total absorvida pelas plantas foi calculada pelo produto da quantidade de matéria seca produzida por vaso e os respectivos teores de $\mathrm{K}$ no tecido vegetal analisado.

Após o quinto corte das plantas de B. ruziziensis, foram coletadas amostras de solo para determinação dos teores de K trocável (Raij et al., 2001) e K não trocável (Knudsen et al., 1982).

A quantidade de K absorvida proveniente de formas não trocáveis foi calculada, após o cultivo de $B$. ruziziensis, pela diferença entre o total acumulado pelas plantas nos cinco cortes e a soma do decréscimo do K trocável (resina) do solo e da quantidade de K adicionada na adubação, considerada trocável para cálculo, como sugerido por Castilhos et al. (2002), conforme a equação:

Quadro 1. Características químicas do solo utilizado no experimento em casa de vegetação em decorrência da adubação potássica residual

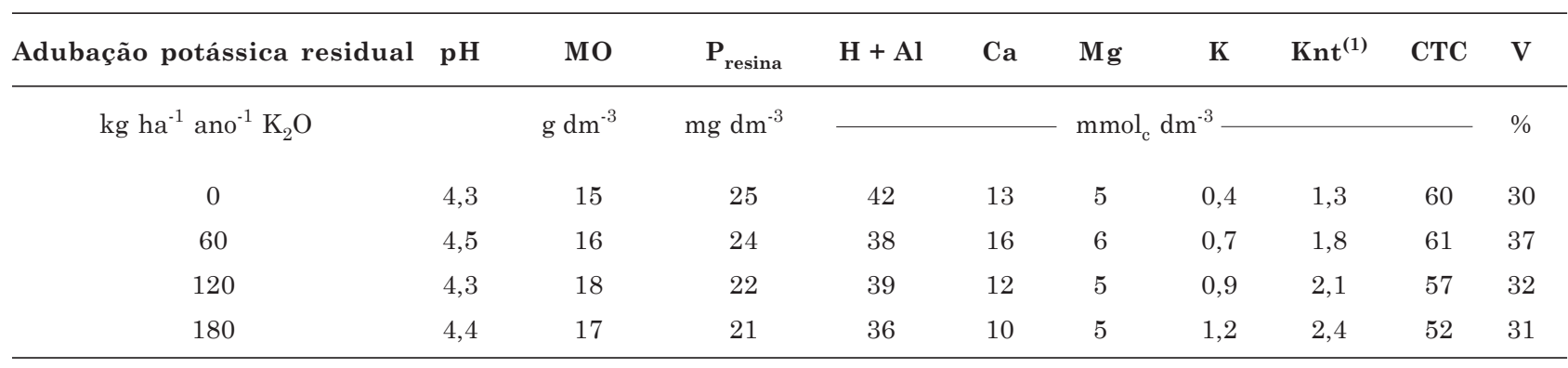

(1) $\mathrm{K}$ não trocável, obtido pela diferença entre o $\mathrm{K}$ extraído com $\mathrm{HNO}_{3} 1 \mathrm{~mol} \mathrm{~L}^{-1}$ fervente e o $\mathrm{K}$ trocável. 
$\mathrm{K}_{\text {Absorvido de Formas Não Trocáveis }}=\mathrm{K}_{\text {Absorvido Total }}$ -
$\left[\left(\mathrm{K}_{\text {Trocável Antes do Cultivo }}-\mathrm{K}_{\text {Trocável Após o Cultivo }}\right)+\mathrm{K}_{\text {Adubação }}\right]$

Os dados foram submetidos à análise de variância, aplicando-se o teste $\mathrm{F}$ a $5 \%$, e, quando os efeitos da adubação potássica residual e da adição complementar de $\mathrm{K}$ foram significativos, as médias foram comparadas pelo teste $t(p<0,05)$. Para comparação dos efeitos dos cortes na produção de matéria seca da parte aérea de $B$. ruziziensis, o critério estatístico empregado foi a comparação de médias, utilizando o intervalo de confiança da média $95 \%(\alpha=0,05)$ (Payton et al., 2000). Nessa técnica, dois tratamentos são considerados significativamente diferentes quando não há sobreposição entre os limites superior e inferior.

\section{RESULTADOS E DISCUSSÃO}

O resultado da análise de variância para a produção de matéria seca da parte aérea e de raízes, $\mathrm{K}$ acumulado nas plantas, teor de $\mathrm{K}$ trocável e $\mathrm{K}$ não trocável no solo é mostrado no quadro 2.

A produção de matéria seca da parte aérea das plantas de B. ruziziensis, nos cinco cortes, foi alterada pela adubação potássica residual na ausência da adição complementar de K (Figura 1a). A maior produção de matéria seca de $B$. ruziziensis foi obtida com o aumento da dose residual de fertilizante potássico e reflete a maior disponibilidade inicial de $\mathrm{K}$ no solo (Quadro 1). Quanto maior o teor inicial de K trocável, maior é a sua disponibilidade para as plantas e, consequentemente, maior a capacidade de produção de matéria seca. Quando houve a adição complementar de fertilizante potássico (Figura 1b,c), a produção de matéria seca da parte aérea das plantas de $B$. ruziziensis mostrou-se semelhante em todos os cortes, independentemente do efeito residual da adubação potássica. Esses resultados indicam que o suprimento de K às plantas depende mais do K recém-adicionado do que do efeito residual da adubação potássica do solo.

Apesar da baixa disponibilidade de $\mathrm{K}$ no solo (Quadro 1), as plantas de B. ruziziensis, sem a aplicação adicional de $\mathrm{K}$, atingiram produção de matéria seca superior a $80 \%$ do rendimento máximo, nos dois primeiros cortes (Figura 1a), reportando à elevada capacidade dessa espécie em extrair $\mathrm{K}$ do solo. Segundo Gommers et al. (2005), quando os mecanismos que controlam a absorção de $\mathrm{K}$ são eficientes, principalmente em baixas concentrações na solução do solo, tem-se como resultado um forte gradiente químico em direção à rizosfera, criando um ambiente favorável à liberação do $\mathrm{K}$ de formas não trocáveis. A partir do terceiro corte, a produção de matéria seca das plantas de $B$. ruziziensis, sem a adição de K, foi reduzida (Figura 1a), indicando que o efeito residual da adubação potássica foi capaz de suprir a necessidade do nutriente por dois cortes. A menor produção de matéria seca de $B$. ruziziensis (Figura 1a), a partir do terceiro corte, pode ser atríbuida ao esgotamento das formas prontamente disponíveis de $\mathrm{K}$ do solo com o decorrer dos cortes sucessivos (Figura 4). Essa inferência também pode ser justificada devido ao aparecimento de sintomas visuais de deficiência de $K$, nas plantas cultivadas sem adição do nutriente.

A produção de matéria seca total da parte aérea das plantas de $B$. ruziziensis acumulada nos cinco cortes, sem o fornecimento de K, variou de 66 a $86 \mathrm{~g} /$ vaso, respectivamente na ausência de efeito residual da adubação potássica (K0) e na dose de $180 \mathrm{~kg} \mathrm{ha}^{-1}$ de $\mathrm{K}_{2} \mathrm{O}$ (K180) (Figura 2a), indicando que na dose residual de $180 \mathrm{~kg} \mathrm{ha}^{-1}$ de $\mathrm{K}_{2} \mathrm{O}$ houve superioridade de $30 \%$ na produção de matéria seca. Com a adição complementar de $\mathrm{K}$, a produção de matéria seca de $B$. ruziziensis nos cinco cortes não foi alterada pelo efeito residual da adubação potássica. A produção de matéria seca variou de 123 a $131 \mathrm{~g} /$ planta e de 150 a $156 \mathrm{~g} /$

Quadro 2. Análise de variância dos efeitos da adubação potássica residual e da adição complementar de K na produção de matéria seca da parte aérea, matéria seca de raízes, quantidade de $\mathrm{K}$ acumulado nas plantas e teor de K trocável e não trocável no solo após o cultivo de Brachiaria ruziziensis (Syn. Urochloa ruziziensis)

\begin{tabular}{|c|c|c|c|c|c|}
\hline \multirow{3}{*}{ Fonte de variação } & \multicolumn{5}{|c|}{ Probabilidade $>$ F } \\
\hline & \multicolumn{2}{|c|}{ Matéria seca } & \multicolumn{3}{|c|}{$\mathbf{K}$} \\
\hline & Parte aérea & Raízes & Acumulado nas plantas & Trocável & Não trocável \\
\hline Bloco & 0,010 & 0,232 & 0,126 & 0,415 & 0,349 \\
\hline Residual (R) & 0,003 & 0,190 & $<0,000$ & $<0,000$ & 0,474 \\
\hline Complementar (C) & $<0,000$ & $<0,000$ & $<0,000$ & $<0,000$ & 0,008 \\
\hline $\mathrm{R} \times \mathrm{C}$ & 0,010 & 0,047 & 0,050 & 0,031 & $<0,000$ \\
\hline CV (\%) & 5,28 & 13,49 & 4,87 & 16,07 & 15,10 \\
\hline
\end{tabular}


planta com a aplicação de 150 e $300 \mathrm{mg} \mathrm{dm}^{-3}$ de $\mathrm{K}$, respectivamente (Figura 2a).

Sem o fornecimento de K, a produção de matéria seca de raízes de $B$. ruziziensis variou de 14 a $33 \mathrm{~g} /$ vaso, na ausência de efeito residual da adubação potássica (K0) e na dose de $180 \mathrm{~kg} \mathrm{ha}^{-1}$ de $\mathrm{K}_{2} \mathrm{O}$ (K180), respectivamente (Figura 2b). Esses dados indicam que na dose residual de $180 \mathrm{~kg} \mathrm{ha}^{-1}$ de $\mathrm{K}_{2} \mathrm{O}$ as plantas mantiveram maior quantidade de raiz ao final dos cinco cortes em comparação ao cultivo de $B$. ruziziensis, na ausência de efeito residual de adubação potássica. Com a adição complementar de K, a
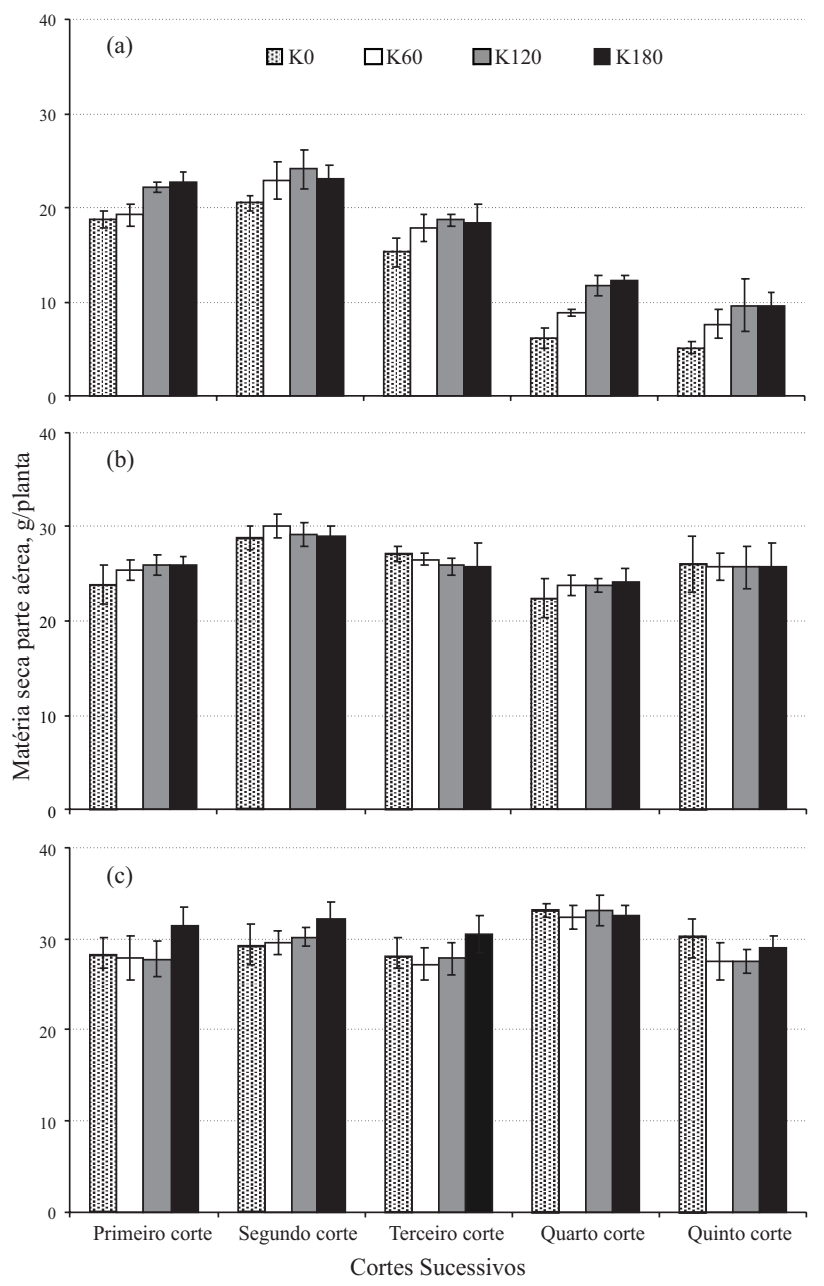

Figura 1. Produção de matéria seca da parte aérea de plantas de Brachiaria ruziziensis (Syn. Urochloa ruziziensis) em cinco cortes, em decorrência da adubação potássica residual e da adição complementar de 0 (a), 150 (b) e 300 (c) $\mathrm{mg} \mathrm{dm}^{-3}$ de $\mathrm{K}$, em experimento de casa de vegetação. Barra vertical representa o intervalo de confiança da média; a ausência de sobreposição dos intervalos de confiança indica diferença estatística significativa $(\alpha=0,05)$. K0, $\mathrm{K} 60, \mathrm{~K} 120$ e K180 representam a dose residual de K (em kg ha-1 ano-1 de $\left.\mathrm{K}_{2} \mathrm{O}\right)$. produção de matéria seca das raízes não foi alterada pelo K residual de adubações anteriores. A produção de matéria seca de raízes, acumulada nos cinco cortes, variou de 77 a $81 \mathrm{~g} /$ planta e de 88 a $96 \mathrm{~g} /$ planta, com a aplicação de 150 e $300 \mathrm{mg} \mathrm{dm}^{-3} \mathrm{de} \mathrm{K}$, respectivamente (Figura 2b).

A quantidade total de $\mathrm{K}$ acumulado pelas plantas (parte aérea + raízes) de B. ruziziensis nos cinco cortes aumentou com o aumento da dose de adubação potássica residual e complementar (Figura 3). O aumento na quantidade de $\mathrm{K}$ acumulada nas plantas com a adubação residual reflete a maior disponibilidade inicial desse nutriente no solo (Quadro 1). Por sua vez, o maior acúmulo de $\mathrm{K}$ nas plantas com o aumento da dose de K complementar pode ser explicado em decorrência do fato de que, sob condições de alta disponibilidade de $\mathrm{K}$ no solo, as plantas absorvem quantidade acima da sua necessidade metabólica, que
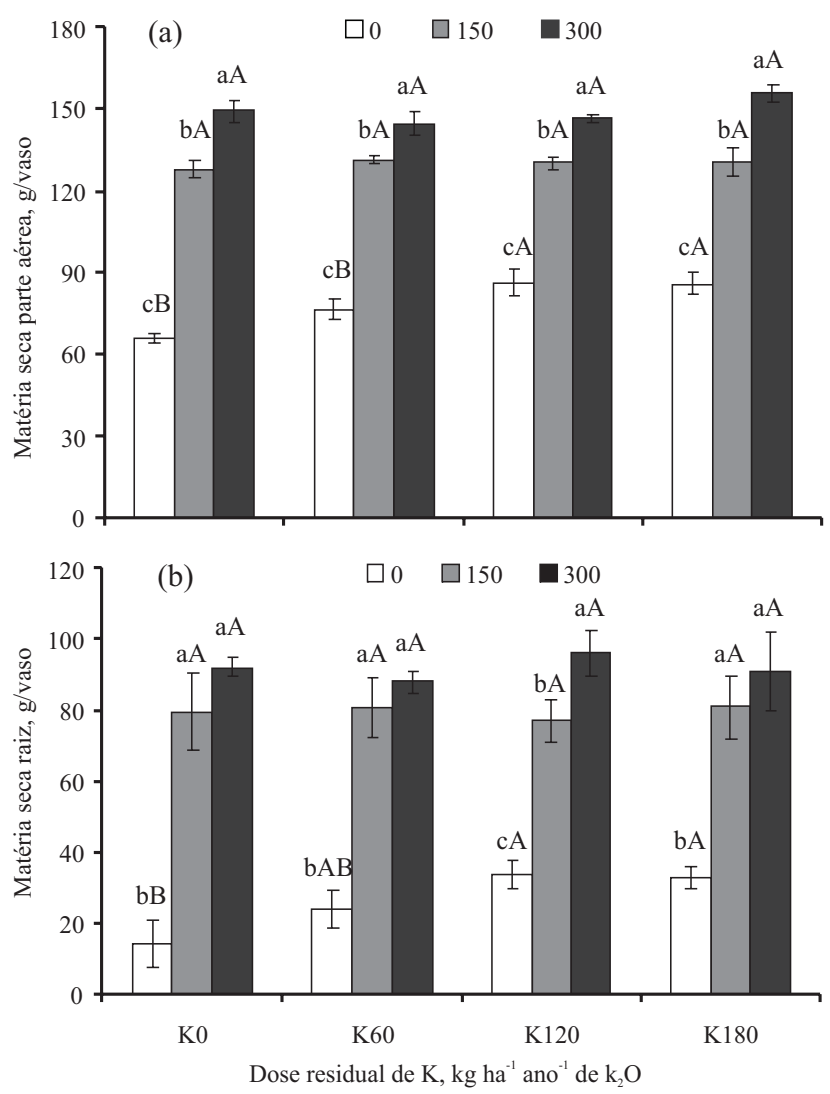

Figura 2. Produção de matéria seca da parte aérea (a) e de raízes (b) de Brachiaria ruziziensis (Syn. Urochloa ruziziensis) acumulada nos cinco cortes, em decorrência da adubação potássica residual e da adição complementar de 0, 150 e $300 \mathrm{mg} \mathrm{dm}^{-3}$ de $\mathrm{K}$. Barra vertical representa o erro-padrão da média $(\mathrm{n}=4)$. Colunas sobrepostas pela mesma letra minúscula, dentro de cada dose de adubação residual, e pela mesma letra maiúscula, dentro de cada dose adicional de $K$, não diferem pelo teste $t$ (LSD) a $5 \%$. 
é acumulada em organelas da célula vegetal (como nos cloroplastos, nas mitocôndrias e, especialmente, nos vacúolos), caracterizando o "consumo de luxo" (Gommers et al., 2005). O aumento do acúmulo de K em plantas em decorrência do efeito residual e, ou, da adubação potássica é normalmente reportado na literatura (Simonete et al., 2002; Kaminski et al., 2007; Fraga et al., 2009).

O menor acúmulo de $\mathrm{K}$ nas plantas, independentemente do efeito residual da adubação, sem a adição complementar do nutriente deve-se ao menor suprimento desse nutriente às plantas ao longo dos cortes sucessivos. Esses resultados são atribuídos ao esgotamento das formas disponíveis do solo com o decorrer do cultivo (Figura 4) e corroboram os resultados obtidos por Kaminski et al. (2007), os quais verificaram que a capacidade de suprimento de $K$ depende mais do $\mathrm{K}$ recém-adicionado do que do histórico de adubação potássica do solo.

Os teores de K trocável e de K não trocável do solo foram alterados pela adubação potássica residual e complementar (Figura 4). O aumento da dose residual de fertilizante potássico elevou o teor inicial de $\mathrm{K}$ trocável (Figura 4a) e de K não trocável (Figura 4b) do solo. $\mathrm{O}$ aumento no teor de $\mathrm{K}$ do solo com a adubação residual pode ser atribuído ao fato de a reposição anual de fertilizante potássico promover maior retenção de $\mathrm{K}$ no solo, além de provocar alterações nos minerais potássicos existentes no solo (Pernes-Debuyser et al., 2003; Simonsson et al., 2009). Após o cultivo de $B$. ruziziensis, independentemente da adição

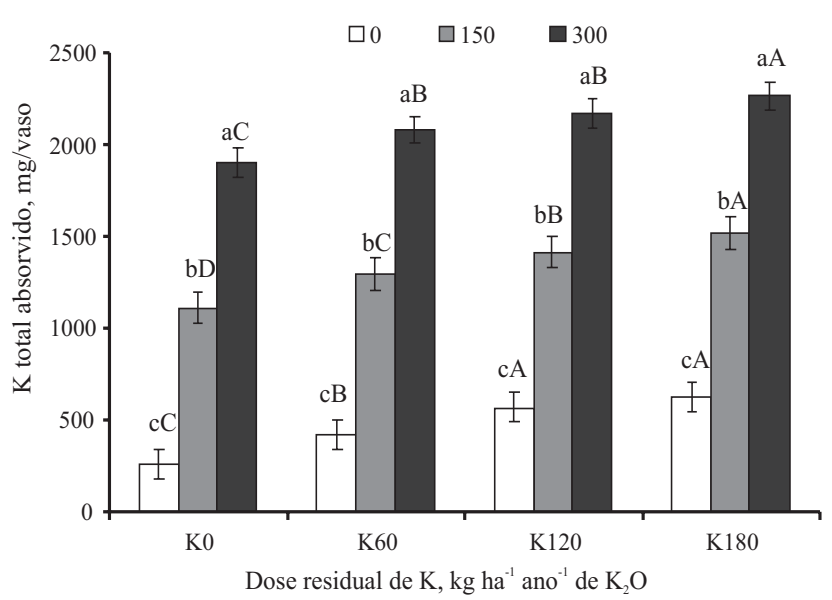

Figura 3. Potássio acumulado nas plantas (parte aérea e raízes) de Brachiaria ruziziensis (Syn. Urochloa ruziziensis) nos cinco cortes, em decorrência da adubação potássica residual e da adição de 0, 150 e $300 \mathrm{mg} \mathrm{dm}^{-3}$ de K. Barra vertical representa o erro-padrão da média $(n=4)$. Colunas sobrepostas pela mesma letra minúscula, dentro de cada dose de adubação residual, e pela mesma letra maiúscula, dentro de cada dose adicional de $K$, não diferem pelo teste t (LSD) a $5 \%$. complementar ou não de fertilizante potássico, houve redução no teor de $\mathrm{K}$ trocável e de K não trocável do solo (Figura 4), indicando que a aplicação total de 150 e $300 \mathrm{mg} \mathrm{dm}^{-3}$ de $\mathrm{K}$ não foi suficiente para suprir o nutriente às plantas e manter constantes os teores do nutriente no solo, o que confirma os resultados obtidos por Moody \& Bell (2006), os quais verificaram que o esgotamento de K no solo cultivado ocorre tanto na forma trocável como na forma não trocável, mesmo quando há adições suficientes de fertilizantes potássicos. Essa diminuição caracteriza exaustão do K nativo do solo ou daquele incorporado pela adubação, em virtude do elevado acúmulo de $\mathrm{K}$ pelas plantas de B. ruziziensis (Figura 3). Por sua vez, com o esgotamento do K nativo, o solo depauperado requer doses maiores de K, suficientes não só para satisfazer
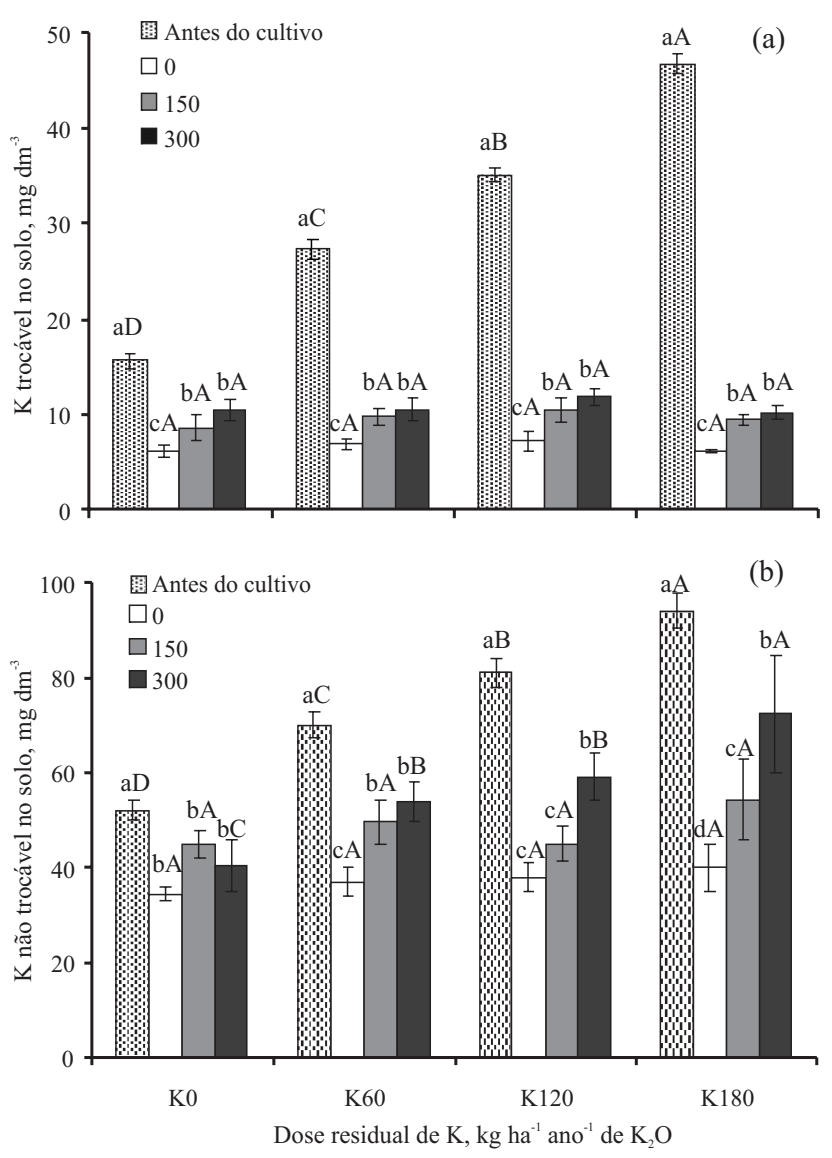

Figura 4. Teor de K trocável (A) e de K não trocável (B) no solo antes e após o cultivo de Brachiaria ruziziensis (Syn. Urochloa ruziziensis), com cinco cortes, em decorrência da adubação potássica residual e da adição complementar de 0,150 e $300 \mathrm{mg} \mathrm{dm}^{-3}$ de $\mathrm{K}$. Barra vertical representa o erro-padrão da média $(n=4)$. Colunas sobrepostas pela mesma letra minúscula, dentro de cada dose de adubação residual, e pela mesma letra maiúscula, dentro de cada dose adicional de $K$, não diferem pelo teste t (LSD) a $5 \%$. 
à demanda da planta, mas também para repor as formas consideradas não trocáveis, que foram utilizadas pela cultura.

O cultivo de plantas, como B. ruziziensis, com elevada capacidade de absorver $\mathrm{K}$ pode influir na relação entre as reservas de $\mathrm{K}$ do solo e na sua disponibilidade, acarretando alterações dos minerais potássicos do solo (Velde \& Peck, 2002; Simonsson et al., 2009). Hinsinger \& Jaillard (1993) verificaram a formação de vermiculita, em detrimento de ilita, no solo da região da rizosfera das raízes de azevém (Lolium multiflorum) em apenas 32 dias de cultivo. Nessa condição, a liberação de K não trocável das entrecamadas da ilita, induzida pela ação das raízes das plantas, foi quase completa. Segundo Kamisnki et al. (2010), a disponibilização de formas de K inicialmente não trocáveis depende mais da demanda das plantas para o nutriente do que das propriedades do solo, como textura e mineralogia. Dessa forma, espécies capazes de induzir a liberação de $\mathrm{K}$ inicialmente de formas não trocáveis - devem ser mais bem investigadas.

O K trocável estabilizou-se com teores mínimos no solo variando de 6,5 a $10,5 \mathrm{mg} \mathrm{dm}^{-3}$, sem e com a adição complementar de K, respectivamente (Figura 4a), indicando que se alcançou equilíbrio entre as formas de K trocável e não trocável com um mínimo de $\mathrm{K}$ no sistema solo-planta. Esses resultados confirmam os reportados por Rosolem et al. (1988), Rosolem et al. (1993), Castilhos \& Meurer (2002), Ernani et al. (2002), Kaminski et al. (2007) e Fraga et al. (2009), segundo os quais, formas não trocáveis de $\mathrm{K}$, ao longo do tempo, podem manter estável o teor de K trocável no solo. No entanto, a manutenção dessa situação por longos períodos pode diminuir as reservas de K do solo e comprometer a reposição deste à solução do solo e o estabelecimento de plantas cultivadas. Além disso, o uso de fertilizantes potássicos com o intuito de aumentar a reserva do $\mathrm{K}$ no solo não se justifica plenamente, pois também há esgotamento dessas formas para suprir a absorção de luxo das plantas. Estudos realizados por Rosolem et al. (1993) em diferentes solos tropicais monstraram acentuado decréscimo nos teores de K trocável do solo no transcorrer de cultivos sucessivos de soja. Estes autores afirmaram ser necessária a utilização de, no mínimo, $80 \mathrm{~kg} \mathrm{ha}^{-1}$ de $\mathrm{K}_{2} \mathrm{O}$ por ano, para evitar o esgotamento das reservas de $\mathrm{K}$ do solo. Assim, o correto manejo da adubação potássica torna-se de extrema importância na preservação da fração não trocável e na manutenção de níveis adequados de disponibilidade de $\mathrm{K}$ para o estabelecimento das culturas.

A contribuição do $K$ proveniente de formas não trocáveis na nutrição potássica das plantas de $B$. ruziziensis foi alterada pela adubação residual e complementar de K (Figura 5). Sem a adição de fertilizante potássico, a contribuição do K não trocável para o total de $\mathrm{K}$ acumulado pelas plantas variou de 78 a 61 \%, na ausência de efeito residual da adubação potássica (K0) e na dose de $180 \mathrm{~kg} \mathrm{ha}^{-1}$ de $\mathrm{K}_{2} \mathrm{O}$ (K180), respectivamente. Esses resultados demonstram a importância das formas de $\mathrm{K}$ inicialmente não trocáveis no suprimento do nutriente às plantas nos sistemas de produção agrícola. A menor contribuição do K não trocável para a nutrição potássica das plantas de $B$. ruziziensis, quando cultivadas na maior dose residual de $\mathrm{K}$, reflete a maior disponibilidade inicial de K trocável no solo (Figura 4a). Com a aplicação adicional de $\mathrm{K}$, a contribuição da forma não trocável variou de 15 a $26 \%$ e de 4 a $11 \%$, com as doses de 150 e $300 \mathrm{mg} \mathrm{dm}^{-3}$ de K, respectivamente (Figura 5). Esses resultados indicam que, mesmo com a aplicação de doses relativamente altas de $\mathrm{K}\left(150\right.$ e $\left.300 \mathrm{mg} \mathrm{dm}^{-3}\right)$, as plantas de $B$. ruziziensis também extraíram formas de K não trocáveis. Essa inferência explica a redução do teor de $\mathrm{K}$ não trocável no solo após os cortes sucessivos (Figura 4b).

Em solo do Rio Grande do Sul, Simonete et al. (2002) estimaram que, mesmo considerando o efeito residual da adubação potássica do azevém na cultura do arroz cultivado em sucessão, houve contribuição da forma não trocável de pelo menos $30 \%$ do K total acumulado pelas plantas. Fraga et al. (2009) verificaram que a contribuição do K não trocável para a nutrição de plantas de arroz variou de 12 a $72 \%$, com e sem adição de $\mathrm{K}$ no primeiro cultivo, respectivamente. A contribuição de formas de $\mathrm{K}$ inicialmente consideradas não trocáveis às plantas comumente é reportada na literatura, mesmo quando há adição de fertilizante potássico (Rosolem et al., 1988; Castilhos \& Meurer, 2002; Calonego et al., 2005; Kaminski et al., 2007; Simonsson et al., 2009). Rosolem et al. (1993) constataram que a forma não trocável, independentemente do solo, foi a principal fonte de K para a soja.

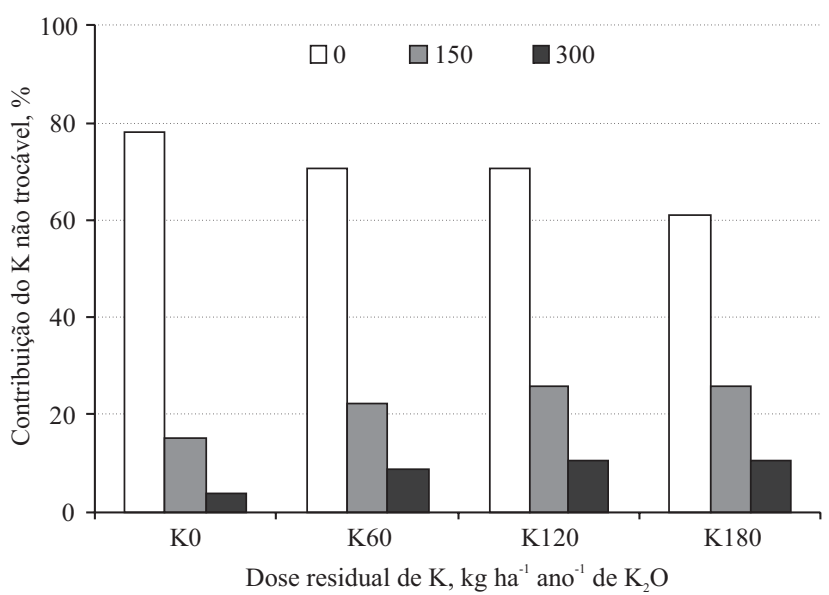

Figura 5. Contribuição do K não trocável na nutrição de plantas Brachiaria ruziziensis (Syn. Urochloa ruziziensis), nos cinco cortes, em decorrência da adubação potássica residual e da adição de 0 , 150 e $300 \mathrm{mg} \mathrm{dm}^{-3}$ de $\mathrm{K}$. 
Em geral, os resultados do presente trabalho confirmam a elevada capacidade de Brachiaria ruziziensis na extração de $\mathrm{K}$ inicialmente presente em formas não trocáveis no solo, como reportado no trabalho de Garcia et al. (2008) para B. brizantha. Esses autores constataram que as plantas de braquiária extraíram quantidades consideráveis de K não trocável do solo, e este $\mathrm{K}$, após dessecação, foi lavado dos resíduos vegetais e retornou ao solo em forma trocável, disponível para o milho cultivado em sucessão. Assim, evidencia-se o importante papel das gramíneas do gênero Brachiaria como culturas de cobertura na ciclagem de $\mathrm{K}$ nos sistemas de rotação de culturas. Além disso, devido à elevada capacidade de recuperação do $\mathrm{K}$ adicionado ao solo, o cultivo de B. ruziziensis, como planta de cobertura, pode ser uma excelente estratégia para o manejo adequado da adubação, principalmente para solos de textura média a arenosa, por minimizar as perdas de $\mathrm{K}$ por lixiviação. Essa inferência deve-se ao fato de que o $\mathrm{K}$ absorvido permanece a maior parte do tempo no tecido vegetal, vivo ou morto, protegido de perdas por erosão e lixiviação. Em solos bem drenados, o K adicionado pela adubação encontra-se sujeito a perdas por lixiviação devido à baixa energia de ligação nos sítios de troca, sobretudo em solos com baixa capacidade de troca de cátions (Rosolem et al., 2006; Ernani et al., 2007; Rosolem et al., 2010), característica da maioria dos solos tropicais do Cerrado brasileiro. Portanto, espécies com elevada capacidade de extrair $\mathrm{K}$ do solo e, ou, capazes de explorar camadas profundas do solo são de extrema importância para a sustentabilidade dos sistemas de produção agrícola, por minimizar as perdas de $\mathrm{K} \mathrm{e}$ manter a fertilidade do solo.

\section{CONCLUSÕES}

1. O potássio residual de adubações anteriores aumentou a quantidade de K acumulada nas plantas de Brachiaria ruziziensis.

2. A capacidade de suprimento de $\mathrm{K}$ às plantas é dependente do fertilizante recém-adicionado.

3. Na ausência de adubação potássica, a forma não trocável foi a principal fonte de $\mathrm{K}$ para as plantas de Brachiaria ruziziensis, confirmando a importância dessa espécie como cultura de cobertura na ciclagem de $\mathrm{K}$ no solo.

\section{AGRADECIMENTOS}

À Fundação de Amparo à Pesquisa do Estado de São Paulo (FAPESP), pelo apoio financeiro para realização do experimento.

\section{LITERATURA CITADA}

CALONEGO, J.; FOLONI, J.S.S. \& ROSOLEM, C.A. Potassium leaching from plant cover straw at different senescence stages after chemical desiccation. R. Bras. Ci. Solo, 29:99108, 2005.

CASTILHOS, D.D.; MEURER, E.J.; KAMPF, N. \& PINTO, L.F.S. Mineralogia e fontes de potássio em solos do Rio Grande do Sul cultivados com arroz irrigado. R. Bras. Ci. Solo, 26:579-587, 2002.

CASTILHOS, R.M.V. \& MEURER, E.J. Suprimento de potássio de solos do Rio Grande do Sul para arroz irrigado por alagamento. R. Bras. Ci. Solo, 26:977-982, 2002.

EMPRESA BRASILEIRA DE PESQUISA AGROPECUÁRIA EMBRAPA. Sistema brasileiro de classificação de solos. 2.ed. Rio de Janeiro, Embrapa Solos, 2006. 306p.

ERNANI, P.R.; BAYER, C. \& ALMEIDA, J.A. Mobilidade vertical de cátions influenciada pelo método de aplicação de cloreto de potássio em solos com carga variável. R. Bras. Ci. Solo, 31:393-402, 2007.

ERNANI, P.R.; DIAS, J. \& FLORES, J.A. Annual additions of potassium to the soil increased apple yield in Brazil. Comm. Soil Sci. Plant Anal., 33:1291-1304, 2002.

FRAGA, T.I.; GENRO JUNIOR, S.A.; INDA, A.V. \& ANGHINONI, I. Suprimento de potássio e mineralogia de solos de várzea sob cultivos sucessivos de arroz irrigado. R. Bras. Ci. Solo, 33:497-506, 2009.

GARCIA, R.A.; CRUSCIOL, C.A.C.; CALONEGO, J.C. \& ROSOLEM, C.A. Potassium cycling in a corn-brachiaria cropping system. Eur. J. Agron., 28:579-585, 2008.

GOMMERS, A.; THIRY, Y. \& DELVAUX, B. Rhizospheric mobilization and plant uptake of radiocesium from weathered soils: I. Influence of potassium depletion. J. Environ. Qual., 34:2167-2173, 2005.

HINSINGER, P. \& JAILLARD, B. Root-induced release of interlayer potassium and vermiculitization of phlogopite as related to potassium depletion in the rhizosphere of ryegrass. Eur. J. Soil Sci., 44:525-534, 1993.

KAMINSKI, J.; BRUNETTO, G.; MOTERLE, D.F. \& RHEINHEIMER, D.S. Depleção de formas de potássio do solo afetada por cultivos sucessivos. R. Bras. Ci. Solo, 31:1003-1010, 2007.

KAMINSKI, J.; MOTERLE, D.V.; RHEINHEIMER, D.S.; GATIBONI, L.C. \& BRUNETTO, G. Potassium availability in a Hapludalf soil under long term fertilization. R. Bras. Ci. Solo, 34:783-791, 2010.

KNUDSEN, D.; PETERSON, G.A. \& PRATT, P.F. Lithium, sodium, and potassium. In: PAGE, A.L., ed.. Methods os soil analysis. 2.ed. Madison, SSSA, 1982. p.225-246.

MALAVOLTA, E.A.; VITTI, G.C. \& OLIVEIRA, A.S. Avaliação do estado nutricional das plantas: princípios e aplicações. Piracicaba, Potafos, 1997. 201p.

MOODY, P.W. \& BELL, M.J. Availability of soil potassium and diagnostic soil tests. Austr. J. Soil Res., 44:265-275, 2006. 
ÖBORN, I.; ANDRIST-RANGEL, Y.; ASKEGAARD, M.; GRANT, C.A.; WATSON, C.A. \& EDWARDS, A.C. Critical aspects of potassium management in agricultural systems. Soil Use Manage., 21:102-112, 2005.

PAYTON, M.E.; MILLER, A.E. \& RAUN, W.R. Testing statistical hypotheses using standard error bars and confidence intervals. Comm. Soil Sci. Plant Anal., 31:547-551, 2000.

PERNES-DEBUYSER, A.; PERNES, M.; VELDE, B. \& TESSIER, D. Soil mineralogy evolution in the INRA 42 plots experiment (Versailles, France). Clays Clay Miner., 51:577-584, 2003.

RAIJ, B.van; ANDRADE, J.C.; CANTARELLA, H. \& QUAGGIO, J.A., ed. Análise química para avaliação da fertilidade de solos tropicais. Campinas, Instituto Agronomico de Campinas, 2001. 285p.

RAIJ, B.van.; CANTARELLA, H.; QUAGGIO, J.A. \& FURLANI, A.M.C. Recomendações de adubação e calagem para o estado de São Paulo. 2.ed. Campinas, Instituto Agronômico de Campinas, 1997. 285p. (Boletim Técnico, 100)

ROSOLEM, C.A.; BESSA, A.M. \& PEREIRA, H.F.M. Dinâmica do potássio no solo e nutrição potássica da soja. Pesq. Agropec. Bras., 28:1045-1054, 1993.

ROSOLEM, C.A.; MACHADO, J.R. \& RIBEIRO, D.B.O. Formas de potássio no solo e nutrição potássica da soja. R. Bras. Ci. Solo, 12:121-125, 1988.

ROSOLEM, C.A. \& NAKAGAWA, J. Potassium uptake by soybean as affected by exchangeable potassium in soil. Comm. Soil Sci. Plant Anal., 16:707-726, 1985.

ROSOLEM, C.A.; SANTOS, F.P.; FOLONI, J.S.S. \& CALONEGO, J.C. Potássio no solo em conseqüência da adubação sobre a palha de milheto e chuva simulada. Pesq. Agropec. Bras., 41:1033-1040, 2006.
ROSOLEM, C.A.; SGARIBOLDI, T.; GARCIA, R.A. \& CALONEGO, J.C. Potassium leaching as affected by soil texture and residual fertilization in tropical soils. Comm. Soil Sci. Plant Anal., 41:1934-1943, 2010.

SIMONETE, M.A.; VAHL, L.C.; FABRES, R.T.; COUTO, J.R.R. \& LUNARDI, R. Efeito residual da adubação potássica do azevém sobre o arroz subseqüente em plantio direto. R. Bras. Ci. Solo, 26:721-727, 2002.

SIMONSSON, M.; ANDERSSON, S.; ANDRIST-RANGEL, Y.; HILLIER, S.; MATTSON, L. \& ÖBORN, I. Potassium release and fixation as a function of fertilizer application rate and soil parent material. Geoderma, 140:188-198, 2007.

SIMONSSON, M.; HILLIER, S. \& ÖBORN, I. Changes in clay minerals and potassium fixation capacity as a result of release and fixation of potassium in long term field experiments. Geoderma, 151:109-120, 2009.

SINGH, M.; SINGH, V.P. \& REDDY, D.D. Potassium balance and release kinetics under continuous rice-wheat cropping system in Vertisol. Field Crops Res., 77:81-91, 2002.

SPARKS, D.L. \& HUANG, P.M. Physical, chemistry of soil potassium. In: MUNSON, R.D., ed. Potassium in agriculture. Madison, Soil Science Society of America, 1985. p.201-276.

VELDE, B. \& PECK, T. Clay minerals changes in the Morrow experimental plots, University of Illinois. Clays Clay Miner., 50:364-370, 2002.

WERLE, R.; GARCIA, R.A. \& ROSOLEM, C.A. Lixiviação de potássio em função da textura e da disponibilidade do nutriente no solo. R. Bras. Ci. Solo, 32:2297-2305, 2008. 